\title{
Host Status of Guardian Peach Rootstock to Meloidogyne sp. and M. javanica
}

\author{
A.P. Nyczepir ${ }^{1}$ and T.G. Beckman ${ }^{2}$ \\ U.S. Department of Agriculture, Agricultural Research Service, Southeastern \\ Fruit and Tree Nut Research Laboratory, 21 Dunbar Road, Byron, GA 31008
}

Additional index words. Prunus persica, resistance, root-knot nematode

Root-knot nematodes (Meloidogyne sp.) are an important pest of peach [Prunus persica (L.) Batsch] in the United States, with $M$. incognita (Kofoid \& White) Chitwood and $M$. javanica (Treub) Chitwood] the predominant species. In South Carolina, M. incognita and $M$. javanica were found in $95 \%$ and $5 \%$ of orchards sampled, respectively (Nyczepir et al., 1997). Root-knot nematodes cause stunted growth, loss of vigor, and early defoliation of 1 - to 2-year-old peach trees when management practices are not followed.

The current preplant nematicide recommendation for managing Meloidogyne sp. in the Southeast includes the soil fumigants, methyl bromide (bromomethane) and 1,3-D (1,3dichloropropene). However, with the pending loss of methyl bromide, alternatives to conventional nematicide application are being investigated. In the Southeast, Lovell peach rootstock is recommended over Nemaguard because trees have a higher survival rate on peach tree short life (PTSL) sites, even though Lovell is susceptible to root-knot nematode. Finding a rootstock superior to Lovell that survives on PTSL sites and also is resistant to root-knot nematode would be of great value to the peach industry throughout the Southeast.

Such a rootstock, BY520-9 (Guardian), was identified in a 1991 trial as providing greater tree survival than Lovell on two PTSL sites through 8 years of evaluation (Okie et al., 1994). Furthermore, recent reports indicate that Guardian rootstock is resistant to $M$. incognita (GA-peach isolate) and M. javanica (NC-tobacco isolate) (Nyczepir et al., 1999).

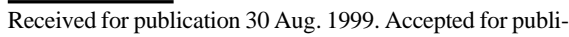
cation 7 Jan. 2000. We thank Michael V. McKenry, UCRiverside, for supplying the $M$. javanica isolate. The cost of publishing this paper was defrayed in part by the payment of page charges. Under postal regulations, this paper therefore mustbe hereby marked advertisement solely to indicate this fact. ${ }^{1}$ ResearchNematologist.E-mail:anyczepir@byronresearch.net ${ }^{2}$ Research Horticulturist.
Additional studies were initiated to examine the susceptibility of Guardian rootstock to two different root-knot nematode populations, M. javanica from California and a species of Meloidogyne from Florida (FL-isolate). The $M$. javanica (CA-isolate) is known to parasitize S-37 peach rootstock, whereas the FLisolate is known to reproduce on Nemaguard. The FL-isolate has an atypical esterase pattern and has not been characterized (Esmenjaud et al., 1997). These nematode populations were of particular interest because both S-37 and Nemaguard are in the pedigree of Guardian. Results of these experiments are reported herein.

Sixteen-day-old Guardian, Lovell, and Nemaguard peach seedlings were transplanted into $10-\mathrm{cm}$-diameter pots containing $450 \mathrm{~cm}^{3}$ of 50 sand : 50 vermiculite (v/v). About 3000 eggs of $M$. javanica were added to each pot 6 d later. The experiment was arranged as a randomized complete-block design with treatments replicated 10 times on a greenhouse bench. Five replications of 'Rutgers' tomato (Lycopersicon esculentum Mill.) also were inoculated with $M$. javanica to ascertain inoculum viability. The experiment was terminated $116 \mathrm{~d}$ after inoculation and the following data were collected: number of egg masses/ root system, number of eggs/root system, number of galls/root system, and dry root weight. The experiment was repeated once.

In another similar greenhouse experiment, Guardian, Lovell, and Nemaguard peach seedlings were established in 10-cm-diameter pots containing 50 sand : 50 vermiculite medium (v/v) to which 3000 eggs of $M$. sp. (FL-isolate) were added. The experiment was terminated $114 \mathrm{~d}$ after inoculation and data were collected as described above. This experiment was repeated once. Changes in the second test included four replications of Rutgers tomato inoculated with $M$. sp. to verify inoculum viability.

Reproduction by $M$. javanica, as indicated by numbers of eggs/plant, eggs/egg mass, and eggs/gram of dry root occurred on all three rootstocks tested. However, reproduction was less $(P \leq 0.05)$ on plants of Guardian and Nemaguard than those of Lovell peach (Table 1). No differences in reproduction occurred between Guardian and Nemaguard. Fewer egg masses/plant were produced on Nemaguard than on Lovell or Guardian in test 2, whereas in test 1 , the number of egg masses were greatest on Lovell, intermediate on Guardian, and least on Nemaguard. Root gall formation by $M$. javanica was less abundant $(P \leq 0.05)$ on Nemaguard than on Lovell and Guardian, but no differences in gall formation were detected between the latter two. Guardian appears to be moderately susceptible to $M$. javanica. Numbers of eggs/tomato plant were 435,000 (test 1) and 252,000 (test 2), indicating viable $M$. javanica inoculum. No differences in reproductive parameters and root gall formation by $M$. sp. were detected among the three rootstocks studied in either test. All three rootstocks were deemed susceptible to $M$. sp. Reproduction on tomato by $M$. sp. was 179,688 eggs/plant (test 2), indicating viable nematode inoculum.

Our results indicate that $M$. javanica and $M$. sp. both reproduce on Guardian rootstock. This is understandable since S-37 (susceptible to $M$. javanica) and Nemaguard (susceptible to $M$. sp.) both occur in the pedigree of Guardian. Studies in France confirm that this $M$. sp. also reproduces on Prunus material derived from Nemaguard (i.e., Nemared and almondpeach hybrids of Garfi x Nemared) (Esmenjaud et al., 1997). Therefore, the parasitic nature of the root- knot nematode isolate must be known when evaluating Prunus rootstocks for resistance. Additional long-term studies are needed to evaluate the effect of these two nematode isolates on growth of Guardian rootstock as compared to local root-knot nematode populations.

\section{Literature Cited}

Esmenjaud, D., J.C. Minot, R. Voisin, J. Pinochet, M.H. Simard, and G. Salesses. 1997. Differential response to root-knot nematodes in Prunus species and correlative genetic implications. J. Nematol. 29:370-380.

Nyczepir, A.P., T.G. Beckman, and G.L. Reighard. 1999. Reproduction and development of Meloidogyne incognita and M. javanica on Guardian peach rootstock. J. Nematol. 31:334-340.

Nyczepir, A.P., R.W.Miller, and T.G. Beckman. 1997. Rootknot nematodes on peach in the southeastern United States: An update and advances. African Plant Protection 3(2):115. (Abstr.)

Okie, W.R., G.L. Reighard, T.G. Beckman, A.P. Nyczepir, C.C. Reilly, E.I. Zehr, W.C. Newall, Jr., and D.W Cain. 1994. Field-screening Prunus for longevity in the southeastern United States. HortScience 29:673-677.

Table 1. Susceptibility of Guardian, Lovell, and Nemaguard peach seedlings to Meloidogyne javanica (CA-isolate) and Meloidogyne sp (FL-isolate) grown in the greenhouse after 116 and $114 \mathrm{~d}$, respectively $(\mathrm{n}=10) .^{\mathrm{z}}$

\begin{tabular}{|c|c|c|c|c|c|c|c|c|c|c|}
\hline \multirow[b]{3}{*}{ Rootstock } & \multirow{2}{*}{\multicolumn{2}{|c|}{$\begin{array}{c}\text { Egg masses } \\
\text { per plant }\end{array}$}} & \multicolumn{6}{|c|}{ Eggs per } & \multirow{2}{*}{\multicolumn{2}{|c|}{ Galls per plant }} \\
\hline & & & \multicolumn{2}{|c|}{ Plant } & \multicolumn{2}{|c|}{ Egg mass } & \multicolumn{2}{|c|}{ Gram of root } & & \\
\hline & Test 1 & Test 2 & Test 1 & Test 2 & Test 1 & Test 2 & Test 1 & Test 2 & Test 1 & Test 2 \\
\hline \multicolumn{11}{|c|}{ Meloidogyne javanica } \\
\hline Lovell & $100 a^{y}$ & $100 \mathrm{a}$ & $65,625 \mathrm{a}$ & $267,000 \mathrm{a}$ & $656 \mathrm{a}$ & $2,670 \mathrm{a}$ & $41,711 \mathrm{a}$ & $131,869 \mathrm{a}$ & $100 \mathrm{a}$ & $100 \mathrm{a}$ \\
\hline Guardian & $30 \mathrm{~b}$ & $100 \mathrm{a}$ & $3,513 \mathrm{~b}$ & $95,000 \mathrm{~b}$ & $129 \mathrm{~b}$ & $950 \mathrm{~b}$ & $3,923 \mathrm{~b}$ & $50,200 \mathrm{~b}$ & $97 \mathrm{a}$ & $100 \mathrm{a}$ \\
\hline Nemaguard & $9 \mathrm{c}$ & $64 \mathrm{~b}$ & $1,056 \mathrm{~b}$ & $57,270 \mathrm{~b}$ & $148 \mathrm{~b}$ & $656 \mathrm{~b}$ & $1,029 \mathrm{~b}$ & $43,434 \mathrm{~b}$ & $74 \mathrm{~b}$ & $87 \mathrm{~b}$ \\
\hline \multicolumn{11}{|c|}{ Meloidogyne sp. } \\
\hline Lovell & $100 \mathrm{a}$ & $58 \mathrm{a}$ & $20,000 \mathrm{a}$ & $13,500 \mathrm{a}$ & $200 \mathrm{a}$ & $232 \mathrm{a}$ & $8,089 \mathrm{a}$ & $4,099 \mathrm{a}$ & $100 \mathrm{a}$ & $100 \mathrm{a}$ \\
\hline Guardian & $83 \mathrm{a}$ & $51 \mathrm{a}$ & $18,125 \mathrm{a}$ & $10,313 \mathrm{a}$ & $285 a$ & $355 a$ & $6,574 \mathrm{a}$ & $2,523 \mathrm{a}$ & $97 \mathrm{a}$ & $87 \mathrm{a}$ \\
\hline Nemaguard & $96 \mathrm{a}$ & $68 \mathrm{a}$ & $18,750 \mathrm{a}$ & $15,625 \mathrm{a}$ & $191 \mathrm{a}$ & $247 \mathrm{a}$ & $10,930 \mathrm{a}$ & $4,650 \mathrm{a}$ & $100 \mathrm{a}$ & $90 \mathrm{a}$ \\
\hline
\end{tabular}

${ }^{2}$ Initial population density of Meloidogyne sp. (FL-isolate) and $M$. javanica $\left(\mathrm{CA}\right.$-isolate) was 3000 eggs $/ 450 \mathrm{~cm}^{3}$ soil. $\mathrm{CA}=\mathrm{California}$ and $\mathrm{FL}=\mathrm{Florida}$.

yean separation within columns and Meloidogyne sp. by LSD, $P \leq 0.05$. 